\title{
Comparative Study of Nutritional Status and Dietary Habits of Children from Public and Private Primary Schools in Zagazig City, Egypt
}

\author{
Amirat Ali El-Sabely ${ }^{1}$, Hanan M. M. Tork ${ }^{2}$ and Yousria El-Sayid Hussien ${ }^{3}$ \\ ${ }^{1,2}$ Department of Pediatric health Nursing, Faculty of Nursing, Zagazig University, Egypt \\ ${ }^{3}$ Department of Community health Nursing, Faculty of Nursing, Minia University, Egypt
}

\begin{abstract}
The future of the society depends on the quality of life of the children. The nutritional status of school aged children impacts their health, cognition and subsequently their educational achievement. The present study was conducted to determine the nutritional status and dietary habits of school aged children (6-12 years) attending public (non-fee paying-NFP) and private (fee paying-FP) primary schools in Zagazig city; capital of Sharqia governorate, Egypt. Based on the World Health Organization (WHO) standard mean of Body Mass Index (BMI), obesity and overweight constituted higher percentage among students in the private school than in the public school, while underweight was high among students in the public school (18.7\%) compared to students in private school (7.5\%). More than half of the public school students (52.7\%) complaining of short stature compared to $27.4 \%$ of the private school students. A statistically significant difference between the two studied groups regarding taking lunch meal $(P$-value $=0.03)$ and the students' preference of eating fried food $(P$-value $=0.00)$ were detected. In conclusion, there were statistically significant differences between the two studied groups regarding their Body Mass Index and daily food consumption.
\end{abstract}

Keywords: Anthropometry, Body Mass Index, Children, Dietary habits, Nutritional status, School age.

\section{Introduction}

Attention to nutritional status is especially important in pediatric patients as they are undergoing the complex processes of growth and development, which are influenced by the genetic makeup of the individual and coexisting medical illness in addition to nutritional status [1]. Nutritional status is the balance between the intake and utilization of food nutrients by man in the process of growth and development [2] and according to Goon et al. is an integral component of the overall health of an individual and provides an indicator of the wellbeing of children living in a particular region [3].

The national researches done in recent years by The Egyptian National Nutrition Institute and other research centres showed that malnutrition is still a major health problem in Egyptian community among different age groups and socio-economic classes [4,5]. School age is the active growing phase of childhood [6]; it represents a dynamic period of physical growth as well as of mental development of the child. Researches indicates that health problems due to miserable nutritional status in school-age children are among the most common causes of low school enrolment, high absenteeism, early dropout and unsatisfactory classroom performance [7].

Malnutrition which refers to an impairment of health either from a deficiency or excess or imbalance of nutrients is public health significance among children all over the world specifically in developing countries $[8,9]$. Globally, malnutrition among school age children is becoming a major public health concern. More than 200 million school age children are stunted and underweight and if no action is taken and at this rate, about one billion school children will be growing up by 2020 with impaired physical and mental development [7, 10-12]. Despite the economic growth observed in developing countries, malnutrition and particularly under nutrition is still highly prevalent [13].

Concurrently, a growing prevalence of obesity and its related chronic diseases is being observed in these countries [14]. In developing countries, this rising epidemic along with the persistence of under nutrition and infections typifies the 'Double Burden of Malnutrition' (DBM) [15], which is becoming of great concern for African countries [16]. Indeed, the DBM is a real threat at the population, household and even individual level [17] and it is now observed among school children [18].

In Egypt, malnutrition disorders affect more than 30\% of school children; this problem appears to be largely attributable to poor dietary quality and micronutrient deficiencies, such as iron and vitamin A [19]. Adequate food and nutrition are essential for proper growth and physical development to ensure optimal work capacity, normal reproductive performance, adequate immune reactions and resistance to infections [8]. On the other hand, inadequate nutrition intake has important implications because malnutrition has been shown to negatively affect the cognitive development of primary school children [19]. 
Recent research at the national level in Egypt revealed a high prevalence of malnutrition among school children [19], therefore, the present study aimed to determine the nutritional status and dietary habits of school aged children (6-12 years) attending public (non-fee paying-NFP) and private (fee paying-FP) primary schools in Zagazig city, Egypt. We hypothesized that malnutrition particularly under nutrition would be widespread, and that public school pupils, would be most affected.

\subsection{Subjects and setting}

\section{Methods}

The present study was carried out between February and April 2013. The data were collected from two primary schools (one public and one private school) both are located in Zagazig city (capital of Sharqia governorate). Necessary approval was obtained from the schools authorities prior to the commencement of the research. Schools were visited once a week; the data was collected by interviewing and examining the children with help of their class teacher. The absentees were examined by visiting the school in next consecutive week. A total of 288 female pupils (182 pupil from public school and 106 pupil from private school) aged 6-12 years were participated in the study. Study was cross-sectional descriptive in nature.

\subsection{Assessment of nutritional status by anthropometry}

To assess the nutritional status of pupils, we measured children weights and heights. Weight was measured to the nearest $0.1 \mathrm{~kg}$ with an electronic scale with children wearing light clothing and without shoes after we checked the scale for accuracy. Individual height was measured with a wooden stadiometer placed on a flat surface. The child stood on the basal part of the device with feet together (without shoes). The shoulders, the buttocks and the heels had to touch the vertical measuring board. A child standing with their eyes in the horizontal plane, the height was measured to the nearest $0.1 \mathrm{~cm}$ and Body Mass Index (BMI) was computed to assess thinness/overweight/obesity and stunting respectively using the WHO reference values [20]. Under weight was defined as body mass index below 18.5, normal weight was defined as body mass index from 18.5 to 24.9 , over weight was defined as body mass index from 25 to 29.9 and obese was defined as body mass index from 30 and above. Dietary habits have been studied depending on the questions addressed regarding repeated ingestion of food in the day and common food groups.

\subsection{Statistical methods}

Quantitative variables were presented as mean, minimum, maximum, SD \& percentiles. Qualitative variables were presented as frequency and percent. Kolmogrov test was used to determine whether the data is parametric or non-parametric, to choose the appropriate test of significance accordingly. Parametric variables were compared between the studied groups using independent sample t-test. Non-parametric variables were compared between the studied groups using Mann-Whitney test. Categorical variables were compared between the studied groups using Chi-square test \& Fisher exact test. Significance level used was 0.05. SPSS statistical package version 20 was used in data analysis.

\section{Results}

A total of 288 children were recruited to the study, 182 of them belonged to public school and 106 belonged to private one. Table (1) reveals that there are statistically significant differences between the both groups of the participated students regarding their age, body mass index and med arm circumference. The same table illustrates the socio-demographic data of the participated students; where $54.7 \%$ of the private school students were the first born child in family compared to $24.2 \%$ of the public school students and these differences related to child's birth order were statistically significant.

Concerning the educational level, highly statistically significant difference was found between parents of the two studied groups; parents of the private school students had higher educational level than parents of the public school students $(53.8 \%, 78.3 \%$ and $23.6 \%, 57.1 \%)$ for mothers and fathers respectively. Concerning the family size, it was found that the most of the private school students $(65.1 \%)$ their family size was less than or equal to five persons, while the most of the students' families in public school $(55.5 \%)$ were ranged between six to nine persons which had a statistically significant difference. 
TABLE-1

Sociodemographic characteristics and body measurements of the studied sample

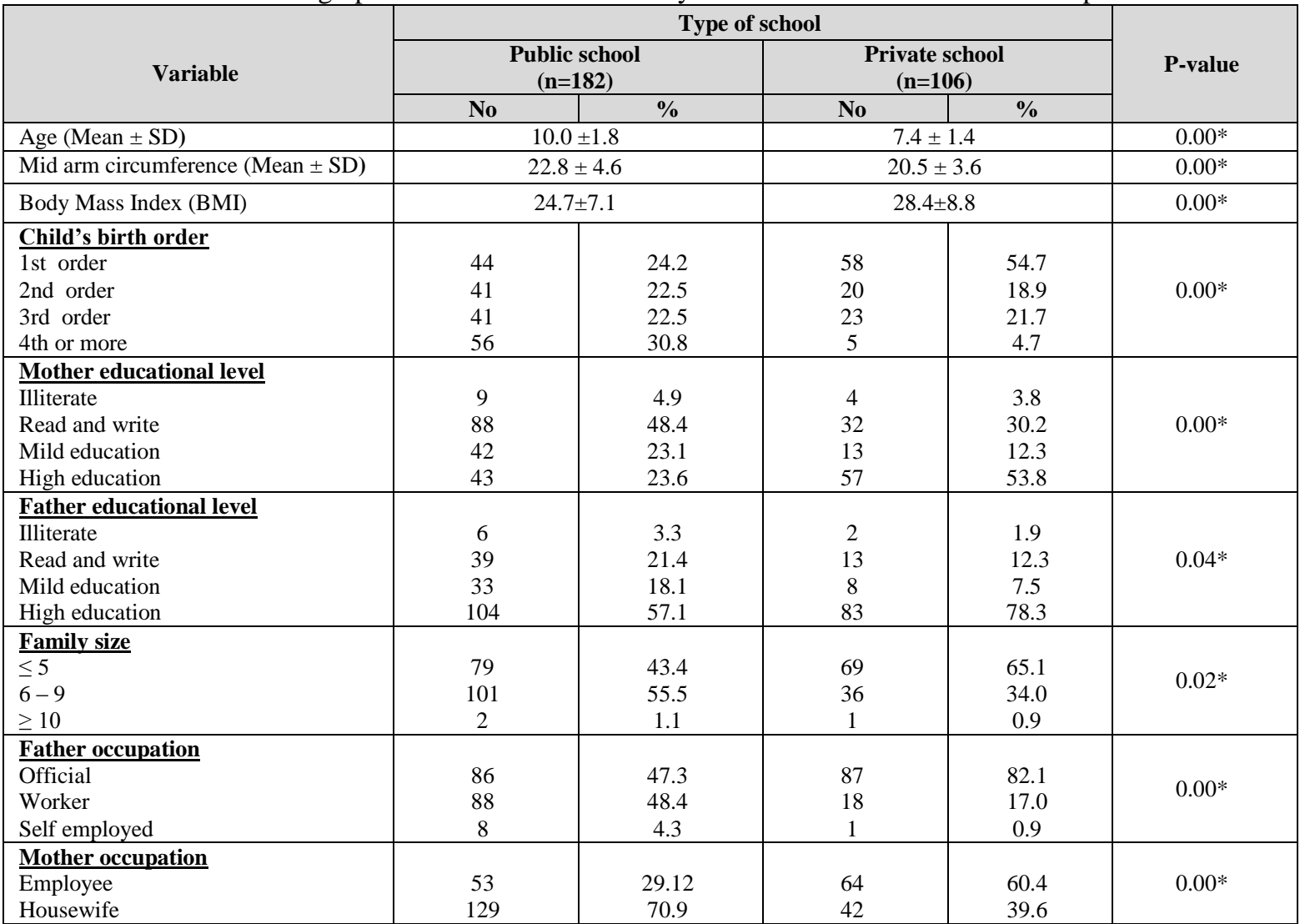

As regards to parents' occupation, the majority of the fathers of the private school students were affiliated to official occupation (82.1\%) compared to $47.3 \%$ of the fathers of the public school students. The same table shows that the majority of the students' mothers of the public school were housewives $(70.9 \%)$ compared to only $39.6 \%$ of the mothers of the students in private school.

TABLE-2

Distribution of the studied sample according to their dietary habits

\begin{tabular}{|c|c|c|c|c|c|}
\hline \multirow{3}{*}{ Variable } & \multicolumn{4}{|c|}{ Type of school } & \multirow{3}{*}{ P-value } \\
\hline & \multicolumn{2}{|c|}{$\begin{array}{c}\text { Public school } \\
(n=182)\end{array}$} & \multicolumn{2}{|c|}{$\begin{array}{c}\text { Private school } \\
(n=106)\end{array}$} & \\
\hline & No & $\%$ & No & $\%$ & \\
\hline $\begin{array}{l}\text { Place of breakfast } \\
\text { Home } \\
\text { School }\end{array}$ & $\begin{array}{c}133 \\
49\end{array}$ & $\begin{array}{l}73.1 \\
26.9\end{array}$ & $\begin{array}{l}78 \\
28\end{array}$ & $\begin{array}{l}73.6 \\
26.4\end{array}$ & 0.93 \\
\hline $\begin{array}{l}\text { Taking breakfast meal } \\
\text { Yes } \\
\text { No }\end{array}$ & $\begin{array}{c}169 \\
13 \\
\end{array}$ & $\begin{array}{c}92.9 \\
7.1 \\
\end{array}$ & $\begin{array}{c}101 \\
5 \\
\end{array}$ & $\begin{array}{c}95.3 \\
4.7\end{array}$ & 0.41 \\
\hline $\begin{array}{l}\text { Taking lunch meal } \\
\text { Yes } \\
\text { No }\end{array}$ & $\begin{array}{c}170 \\
12 \\
\end{array}$ & $\begin{array}{c}93.4 \\
6.6 \\
\end{array}$ & $\begin{array}{c}105 \\
1\end{array}$ & $\begin{array}{c}99.1 \\
0.9 \\
\end{array}$ & $0.03 *$ \\
\hline $\begin{array}{l}\text { Taking dinner meal } \\
\text { Yes } \\
\text { No }\end{array}$ & $\begin{array}{c}171 \\
11 \\
\end{array}$ & $\begin{array}{c}94.0 \\
6.0 \\
\end{array}$ & $\begin{array}{c}101 \\
5\end{array}$ & $\begin{array}{c}95.3 \\
4.7\end{array}$ & 0.64 \\
\hline $\begin{array}{l}\text { Eating fried food } \\
\text { Yes } \\
\text { No }\end{array}$ & $\begin{array}{c}112 \\
70\end{array}$ & $\begin{array}{l}61.5 \\
38.5\end{array}$ & $\begin{array}{l}87 \\
19 \\
\end{array}$ & $\begin{array}{l}82.1 \\
17.9\end{array}$ & $0.00^{*}$ \\
\hline $\begin{array}{l}\text { Prefer eating chips } \\
\text { Yes } \\
\text { No }\end{array}$ & $\begin{array}{c}141^{\prime} \\
41\end{array}$ & $\begin{array}{l}77.5 \\
22.5\end{array}$ & $\begin{array}{l}76 \\
30\end{array}$ & $\begin{array}{l}71.7 \\
28.3\end{array}$ & 0.27 \\
\hline
\end{tabular}

Regarding the students' dietary habits, table (2) illustrates a statistically significant difference between the two studied groups regarding taking lunch meal $(\mathrm{P}-\mathrm{value}=0.03$ ). Concerning the students' preference of eating fried 
food, it was found that the majority of the private school students $(82.1 \%)$ prefer eating fried foods compared to $61.5 \%$ of the public school students and this difference was statistically significant. No statistically significant difference between the both participated groups regarding students' preference of eating chips was found.

TABLE-3

Distribution of the studied sample according to performing domestic activity, practicing exercise and ways of transportation to school

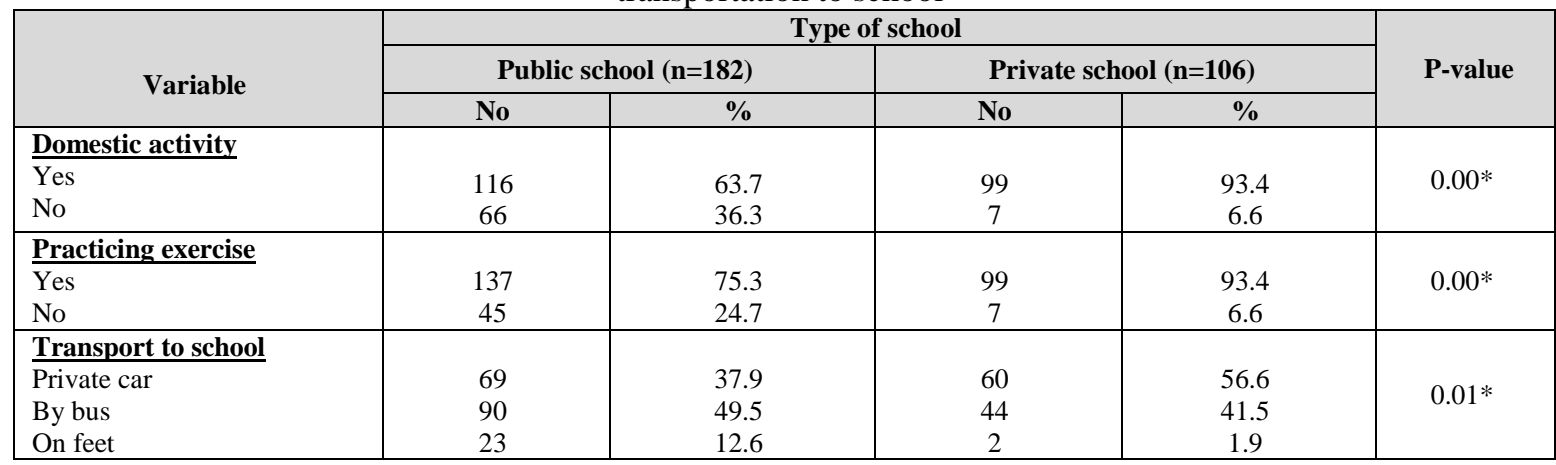

Table (3) reveals that $63.7 \%$ of the public school students and $93.4 \%$ of the private school students performing some of the domestic activities such as buying from supermarkets, carrying children and cleaning home, this represented a statistically significant difference between the both groups. Practicing sports constitutes $93.4 \%$ of the private school students compared $75.3 \%$ of the public school students and this difference is statistically highly significant. Regarding transportation to school, it was found that $12.6 \%$ of public school students compared to $1.9 \%$ of private school students go to school on foot and this difference was statistically significant.

\section{TABLE-4}

Distribution of the studied sample according to their anthropometric measurements

\begin{tabular}{|c|c|c|c|c|c|c|c|c|c|}
\hline \multirow[b]{2}{*}{ Variable } & \multicolumn{3}{|c|}{ Height for age } & \multirow[b]{2}{*}{ P-value } & \multicolumn{4}{|c|}{ BMI } & \multirow[b]{2}{*}{ P-value } \\
\hline & $\begin{array}{c}\text { Normal } \\
\mathbf{N}(\%)\end{array}$ & $\begin{array}{l}\text { Short } \\
\text { N }(\%)\end{array}$ & $\begin{array}{l}\text { Tall } \\
\text { N }(\%)\end{array}$ & & $\begin{array}{l}\text { Normal } \\
\text { N }(\%)\end{array}$ & $\begin{array}{c}\text { Underweight } \\
\mathbf{N}(\%)\end{array}$ & $\begin{array}{c}\text { Over } \\
\text { weight } \\
\text { N }(\%)\end{array}$ & $\begin{array}{l}\text { Obese } \\
\mathbf{N}(\%)\end{array}$ & \\
\hline $\begin{array}{l}\text { Public school } \\
(n=182)\end{array}$ & $82(45.1)$ & $96(52.7)$ & $4(2.2)$ & \multirow{3}{*}{0.00} & 71(39) & $34(18.7)$ & $36(19.8)$ & $41(22.5)$ & \multirow{3}{*}{0.024} \\
\hline $\begin{array}{l}\text { Private school } \\
(n=106)\end{array}$ & $75(70.8)$ & $29(27.4)$ & 2(1.9) & & $38(35.8)$ & $8(7.5)$ & $24(22.6)$ & $36(34)$ & \\
\hline Total $(n=288)$ & $157(54.5)$ & $125(43.4)$ & $6(2.1)$ & & $109(37.9)$ & $42(14.6)$ & $60(20.8)$ & $77(26.7)$ & \\
\hline
\end{tabular}

Regarding the anthropometric measurements, table (4) shows that more than half of the public school students $(52.7 \%)$ complaining of short stature compared to $27.4 \%$ of the private school students and this difference was statistically significant. As observed from the same table, obesity and overweight constitutes highest percentage in the private school students than the public school; $34 \%, 23 \%$ for the private school students and $22.5 \%, 19.8 \%$ for the public school students. The percentage of underweight among public school students was high $(18.7 \%)$ compared to the students of private school $(7.5 \%)$ and these differences were statistically significant.

TABLE-5

Distribution of the studied sample according to daily food consumption

\begin{tabular}{|c|c|c|c|}
\hline \multirow{3}{*}{ Variable } & \multicolumn{2}{|c|}{ Type of school } & \multirow{3}{*}{ P-value } \\
\hline & $\begin{array}{c}\text { Public school } \\
\quad \mathrm{N}=182\end{array}$ & $\begin{array}{c}\text { Private school } \\
\mathbf{N}=\mathbf{1 0 6}\end{array}$ & \\
\hline & Mean \pm SD & Mean \pm SD & \\
\hline Carbohydrates & $2.6 \pm 0.8$ & $2.7 \pm 1.1$ & 0.21 \\
\hline Cereals & $1.6 \pm 0.7$ & $1.6 \pm 0.8$ & 0.99 \\
\hline Meat & $1.6 \pm 0.8$ & $1.9 \pm 1.1$ & $0.06^{*}$ \\
\hline Milk & $2.1 \pm 0.8$ & $1.9 \pm 0.8$ & 0.18 \\
\hline Vegetables & $2.2 \pm 1.0$ & $2.3 \pm 1.2$ & 0.47 \\
\hline Fruits & $1.7 \pm 1.0$ & $2.0 \pm 0.9$ & $0.04 *$ \\
\hline
\end{tabular}




\begin{tabular}{|l|c|c|c|}
\hline Juice & $2.2 \pm 0.9$ & $2.0 \pm 1.1$ & 0.12 \\
\hline Candies & $2.1 \pm 1.0$ & $1.7 \pm 1.0$ & $0.01 *$ \\
\hline
\end{tabular}

As regards to the daily food consumption, table 5 shows that statistically significant differences were found between the two groups of studied sample regarding the daily consumption of Meat, fruits and candies.

\section{Discussion}

School age is considered as a dynamic period of growth and development because children undergo physical, mental, emotional and social changes. In other words the foundations of good health and sound mind are laid during the school age period [7]. Hence the present study was formulated with the objective, to determine the nutritional status and dietary habits of school aged children (6-12 years) attending public and private primary schools.

Irrespective of the type of school or socioeconomic state, the nutritional status of the participated students was not acceptable; where the findings revealed that $62.2 \%$ of all participants fell below or over the class regarded as normal nutritional status using the World Health Organization BMI norms [20]. In spite of that, the findings related to some aspects were much better than other previous studies. Emam et al. [4] conducted his study among the school age students in Giza, Egypt and reported that underweight as high as $76.9 \%$ for urban and $69.3 \%$ for rural areas compared to $14.6 \%$ for the present study.

The students attending private schools are with a good socioeconomic status and their nutritional status had always been better than the students attending public schools [21]. The present study compared nutritional status of school children in the public and private primary schools in Zagazig city were compared, the results showed that there was a significant difference between them regarding the BMI, children in private primary school had a higher mean value of $28.4 \pm 8.8 \mathrm{kgm}$ than that of the children of public primary school who had a mean value of $24.7 \pm 7.1 \mathrm{kgm}$. This finding is supported by the findings of Olanipekun et al. [22], who found that the nutritional status of children in private (fee paying) primary schools in Ibadan was higher than these children in the public (Non fee paying) primary schools.

Although there was no statistically significant difference between the students in public and private schools regarding the consumption of vegetables, carbohydrates and milk, the statistically significant differences were detected regarding the consumption of Meat and fruits; perhaps it may be a reflection of the economic strength of the family.

In addition, the findings revealed that most of the parents of the children in public schools are workers and have a large family size which indicates low income earners while those of the children in the private schools are affiliated to official occupation and small family size which may indicates high income earners. In other words, the parents of the children in the private primary schools would be able to afford the foods containing the necessary nutrients for their children while the parents of the low-income may not be financially adequate to afford such food items for their children. These findings are in accordance with other international studies [2, 23], which concluded that nutritional status is significantly related to income and educational background of the parents.

In the same context, the present study demonstrated that more than half of the mothers of students in private school had high education comparing to less than quarter of the mothers of students in public school. This result also in agreement with Nabag [24] and Ahmed [25] who conducted their studies in Sudan among the same age group and reported that Mothers' educational level as important underlying determinants that directly or indirectly cause malnutrition among children.

\section{Ethical Approval}

This study was approved by the administrator of the educational district to which it belongs schools participating in the study following the normal procedure. Study aim, plan and benefits were explained to each school director to obtain his/her approval. Written consent was obtained from parents before starting the data collection by sending it through their children with brief explanation about the study and the nature of the required data. Oral consent was obtained from the participated students and confidentiality was maintained at all times.

\section{Recommendations}

Regular weight and height measurements should be taken in the school so that a regular check can be kept on the development of the children. Based on the need of the children of a particular school intervention programmes should be developed and implemented. There is a great need for further researches to provide the data regarding nutritional status of different age group. 


\section{References}

[1] Maqbool A, Olsen I E., Stallings VA. "Clinical Assessment of Nutritional Status" Duggan C, et al. Nutrition in Pediatrics. 4th ed. Hamilton, Ontario, Canada: BC Decker Inc; 2008, PP.5-13.

[2] Adegun J.A, Ajayi-Vincent O.B, and Alebiosu E.O. Differences in the nutritional status of young school children from public and private owned primary schools in Ekiti state, Nigeria. European Scientific Journal. 9(7), 2013.

[3] Goon, T.D, Toriola L.A, Shaw S.B, Amusa O. L, Monyeki A.M, Akinyemi O. and Alabi, A.O. anthropometrically determined nutritional status of urban primary school children in Makurdi, Nigeria. BMC Public Health. Vol. 11, 2011, 769.

[4] Emam S, Mostafa R, Wassef O, Mansour E, Khalaf N, Ahmed N, Alsewafy I, Ahmed Alhenawy A, and Mahmoud Z. Assessment of Nutritional Status of Some Primary School Children \& Their Awareness in Slum Areas. Alexandria Journal of Pediatrics, Volume 19 (1), 2005, 113-119.

[5] World Health Organization. Country cooperation Strategy for WHO and Egypt 2010-2014. WHO Regional Office for the Eastern Mediterranean, Cairo, 2010. Available at http://www.who.int/countryfocus/cooperation_strategy/ccs_egy_en.pdf. (Accessed 25 October 2013).

[6] UNICEF, The State of World's Children, 2004. Available at http://www.unicef.org/sowc04/files/SOWC_O4_eng.pdf (accessed 5 October 2012).

[7] Srivastava A., Mahmood S.E., Srivastava P. M., Shrotriya V. P and Kumar B. Nutritional status of school-age children - A scenario of urban slums in India. Archives of Public Health ,2012, 70:8

[8] Amuta, Une E., Houmsou and Soumay R. Assessment of Nutritional Status of School Children in Makurdi, Benue State. Pakistan Journal of Nutrition, 8, 2012, 691-694.

[9] Sati V. and Dahiya S. Nutritional Assessment of Rural School-Going Children (7-9 Years) of Hisar District, Haryana. 1 (7), 2012, 1:363. Doi: 10.4172/ scientificreports.363.

[10] Ara R, Huque SR, Adhikary M, Uddi MN, Mahmood AR, et al. Nutritional status among primary school children in a selected rural community. J Dhaka Med Coll 20, 2011, 97-101.

[11] Mekonnen H, Tadesse T, and Kisi T. Malnutrition and its Correlates among Rural Primary School Children of Fogera District, Northwest Ethiopia. J Nutr Disorders Ther. 2013, S12: 002. doi:10.4172/2161-0509.S12-002.

[12] UNICEF. Levels and Trends in Child Mortality: Estimates Developed by the UN Inter- agency Group for Child Mortality Estimation, 2011.

[13] Muller O, and Krawinkel M. Malnutrition and health in developing countries. Cmaj, 173(3), 2005, 279-286.

[14] Prentice A.M. The emerging epidemic of obesity in developing countries. Int J Epidemiol, 35(1), 2006, 93-99.

[15] FAO [food and agriculture organization of the United Nations]. The double burden of malnutrition: Case studies from six developing countries. Food and nutrition paper No84, Rome, 2006.

[16] Thiam I, Samba K, and Lwanga D. Diet related chronic disease in the West Africa Region. In Diet-related chronic diseases and the double burden of malnutrition in West Africa. SCN News, 33, 2006, 6-10.

[17] Delisle H.F. Poverty: the double burden of malnutrition in mothers and the intergenerational impact. Ann N Y Acad Sci, 1136 2008, 172-184.

[18] Fernald L.C. and Neufeld L.M. Overweight with concurrent stunting in very young children from rural Mexico: prevalence and associated factors. Eur J Clin Nutr, 61(5), 2007, 623-632.

[19] Galal OM, Ismail I, Gohar AS, Foster Z. Schoolteachers' awareness about scholastic performance and nutritional status of Egyptian schoolchildren. Food Nutr Bull. Jun; 26(2 Suppl 2), 2005, S275-80.

[20] WHO Expert Consultation. Appropriate body-mass index for Asian populations and its implications for policy and intervention strategies. Lancet. Jan 10; 363(9403), 2004, 157-63.

[21] Wickramasinghe1 VP, Lamabadusuriya SP, Atapattu N, Sathyadas1 G, Kuruparanantha S and Karunarathne P, (2004) Nutritional status of schoolchildren in an urban area of Sri Lanka. Ceylon Medical Journal. Vol. 49, No. 4, 114-118.

[22] Olanipekun O.T, Obatolu A.V, Fasoyiro B.S \& Ogunba, O.B (2012). Assessment of nutritional status of primary school children in Ibadan, southwest Nig. Nutrition and Food Science, Vol, 42 Iss. 6.

[23] Manandhaar N, Krishna G, \& Patoway S. Nutritional status of Primary School Children. Journal of Institute of Medicine. 30 ( 2), 2008,

[24] Nabag FO. Comparative Study of Nutritional Status of Urban and Rural School Girl's Children Khartoum State, Sudan. Journal of Science and Technology, 12 (02), 2011,60-68.

[25] Ahmed A. F. Assessment of the Nutritional Status of Primary School Children Aged 6-12 Years in Khartoum Area. M.Sc. Thesis, Ahfad University for woman, Khartoum, Sudan, 2003. 